\title{
An occurrence of a fully-oxidized natural titanomaghemite in basalt
}

\author{
Jacqueline E. M. Allan, J. M. D. Coey and I. S. Sanders \\ Physics Department, Trinity College, Dublin 2, Ireland \\ U. SCHWERTMANN \\ Institut für Bodenkunde, Freising-Weihenstephan, West Germany \\ G. FRIEDRICH AND A. WIECHOWSKI \\ Institut für Mineralogie und Lagerstättenlehre, Aachen, West Germany
}

\begin{abstract}
Titanomaghemite occurs in a relatively fresh doleritic intrusion in an area of Precambrian gneiss in Minas Gerais, Brazil. It hosts exsolution lamellae of ilmenite and contains more than $90 \%$ of the iron in the ferric form. It is more resistant to weathering than the ilmenite and is inherited virtually unaltered by the resulting soils. Titanomaghemite, extracted as grains from a weathered rind of the rock, has lattice parameter $a_{0}=0.8348(3) \mathrm{nm}$ and has a canted spin structure due to substitution of non-magnetic ions on tetrahedral and octahedral sites of the spinel structure. The average canting angle is $32 \pm 3^{\circ}$ and canting occurs predominantly on the octahedral iron sublattice. Its formula, based on microprobe analysis and Mössbauer spectroscopy may be expressed as:
\end{abstract}

$$
\left[\mathrm{Fe}_{0.77} \mathrm{Ti}_{0.22} \mathrm{Zn}_{0.01}\right]\left\{\mathrm{Fe}_{1.19} \mathrm{Ti}_{0.26} \mathrm{Mn}_{0.02} \mathrm{Al}_{0.04} \square_{0.49}\right\} \mathrm{O}_{4}
$$

where [] and \{\} denote ions on tetrahedral and octahedral sites, respectively. The spontaneous magnetization of the mineral is $36(3) \mathrm{J} / \mathrm{T} / \mathrm{kg}$.

KEYWoRDS: titanomaghemite, ferric iron, gneiss, Minas Gerais, Brazil.

\section{Introduction}

Maghemites are cation-deficient iron oxides with a structure related to that of spinel, which contain little or no ferrous iron. The ideal formula, $\gamma-\mathrm{Fe}_{2} \mathrm{O}_{3}$ may be written

$$
\left[\mathrm{Fe}^{3+}\right]\left\{\mathrm{Fe}_{5 / 3}^{3+3} \square_{1 / 3}\right\} \mathrm{O}_{4}
$$

where [] and \{\} denote, respectively, tetrahedral $(A)$ and octahedral $(B)$ sites of the spinel structure, and $\square$ represents a vacancy. There is a solidsolution series between magnetite, $\mathrm{Fe}_{3} \mathrm{O}_{4}$, and maghemite, which converts to hematite, $\alpha-\mathrm{Fe}_{2} \mathrm{O}_{3}$, on heating to about $300^{\circ} \mathrm{C}$. Both cation (e.g. $\mathrm{Al}, \mathrm{Ti})$ and anion $(\mathrm{OH})$ substitutions are common in the structure, and a range of lattice parameters $\left(0.830 \leqslant a_{0} \leqslant 0.835 \mathrm{~nm}\right)$ is found in the literature (Lindsley, 1976). The term titanomaghemite refers to cation-deficient spinels in the $\mathrm{Fe}^{3+}$-rich field defined by $\mathrm{Fe}_{3} \mathrm{O}_{4}-\mathrm{Fe}_{2} \mathrm{TiO}_{4}-\mathrm{FeTiO}_{3}-\gamma$ $\mathrm{Fe}_{2} \mathrm{O}_{3}$.

Mineralogical Magazine, June 1989, Vol. 53, pp. 299-304 (C) Copyright the Mineralogical Society
Titanomaghemite occurs extensively in seafloor basalts, where it usually forms by gradual undersea alteration of titanomagnetite produced at the mid-ocean ridge, with a time-constant of about $10^{6}$ years (Johnson and Atwater, 1977). Partial oxidation of titanomagnetite may also take place at high temperatures and be retained as the basalt is quenched (Hauptmann, 1974). Occurrences are also reported in seamounts (Kono et al., 1980) and subaerial volcanic rocks (Akimoto and Kushiro, 1960).

Maghemite in soils can be formed from goethite by burning in the presence of biomass. Such goethite is frequently aluminous, and aluminium will then be incorporated into the structure of maghemite (Schwertmann and Fechter, 1984; Fitzpatrick, 1988). There is also some evidence of the possible formation of soil maghemite by a solution-precipitation process (Kopp and Lee, 1987). Highly magnetic soils, often reported to 
contain maghemite, are widespread in Brazil (Resende et al., 1988, Curi and Franzmeier, 1987). They frequently form on basalt, and magnetization is used there as an aid in soil classification.

Here we report the presence of fully-oxidized titanomaghemite in a relatively fresh, intrusive rock of basaltic composition from an area of Precambrian gneiss in Minas Gerais, Brazil. The rock is the parent for a soil with a high concentration of magnetic material, as described by Resende et al. (1986). We have determined the composition, intrinsic magnetization and spin structure of this titanomaghemite, which will facilitate its quantitative determination by magnetic measurements.

\section{Experimental methods}

Electron microprobe measurements were made with a wavelength dispersive ARL-SEMQ. The excitation potential was $20 \mathrm{kV}$, the beam current $20 \mathrm{nA}$ and the take-off angle was $52.5^{\circ}$. Natural standards were used and the data were corrected using the modified program Magic IV (Colby, 1968).

The samples were analysed by X-ray diffraction (XRD) with $\mathrm{Co}-K \alpha$ radiation using a Philips powder diffractometer. An internal silicon standard was used and the step size was $0.02^{\circ} 2 \theta$ per step. The data were computer fitted using standard XRD fitting programs.

V4

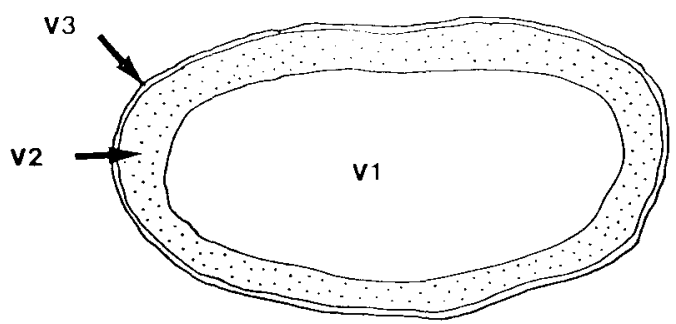

FIG. 1. Schematic diagram of the doleritic cobble ( $\leqslant 10 \mathrm{~cm}$ in length) showing: V1, rock of basaltic composition containing magnetic grains $\mathrm{V} 1 \mathrm{~m}$; V2, yellow rind of weathered material containing magnetic grains $V 2 \mathrm{~m}$; V3, red outer rind; V4, surrounding red magnetic soil.

Room-temperature magnetization measurements were made in fields up to 1.5 Tesla using a vibrating sample magnetometer. ${ }^{57} \mathrm{Fe}$ Mössbauer spectra at room temperature and $4.2 \mathrm{~K}$ were collected in 512 channels using a conventional constant acceleration spectrometer and a source of ${ }^{57} \mathrm{Co}$ in $\mathrm{Rh}$.

\section{Results}

Petrographic examination. The intrusion is located in the hilly to mountainous region of the Zona da Mata, Minas Gerais, Brazil. The area is formed of Precambrian gneiss with minor mafic intrusions and has a deep weathering mantle $(\gg 10 \mathrm{~m}$ ). Cobble-sized ( $\leqslant 10 \mathrm{~cm}$ maximum dimension) rounded pieces of dolerite (see Fig. 1), which are distributed throughout the weathering mantle, were examined. The cobbles are surrounded by rinds of yellow weathered material (containing quartz, gibbsite, and goethite) several millimetres thick.

In thin section, the dolerite is mainly fresh with occasional weathered patches associated with fractures ( $\approx 5 \%$ of total area). The fresh rock contains approximately $65 \%$ plagioclase feldspar, $30 \%$ pyroxene, and $5 \%$ opaque minerals, and is non-porphyritic. The plagioclase forms laths $1-$ $1.5 \mathrm{~mm}$ long and falls within the labradorite range, with $50-70 \%$ of the calcic end-member (anorthite). The pyroxene crystals (grain size $\leqslant 0.5 \mathrm{~mm}$ ) are of pale augite and show some strain deformation into sub-grains; they form polycrystalline clusters $(\leqslant 1.5 \mathrm{~mm})$ and are generally interstitial to the plagioclase. The opaques (grain size $\leqslant 1 \mathrm{~mm}$ ) are irregularly shaped and partly interstitial, providing evidence that they may have formed later than the other rock components. The opaque grains are of ilmenite and of magnetite/ maghemite (a spinel-structure phase) with ilmenite exsolution parallel to $\{111\}$. A characteristic lamellar structure (Putnis and McConnell, 1980) is clearly seen in the dolerite and in grains extracted from the weathered rind (Fig. 2), with approximately $20 \%$ of the area of the opaque grains being ilmenite and the rest magnetite/maghemite. We show later that the latter phase is actually maghemite.

In the weathered patches, near fractures, the rock has been heavily altered to an orange and brown birefringent material which may include goethite and oxidized chlorite.

Electron microprobe. Opaque mineral grains from both the basalt (V1m) itself and from the surrounding yellow rind (V2m) were analysed. Five to eight points were examined in the ilmenite and maghemite regions and the results averaged (see Table 1). 


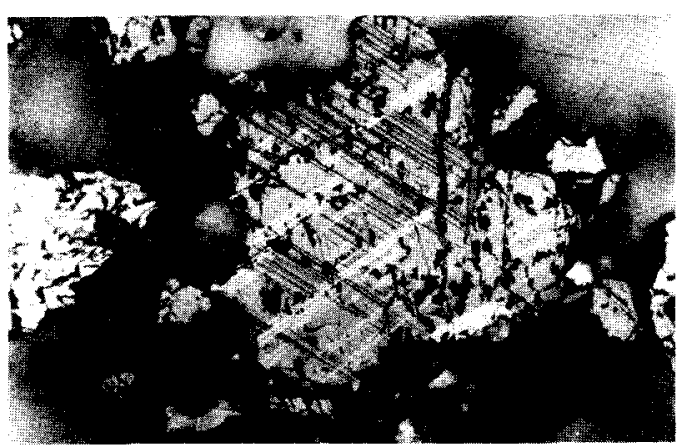

FIG. 2. Photograph of a grain of $\mathrm{V} 2 \mathrm{~m}$, under slightly uncrossed polarizers, showing exsolution lamellae of ilmenite (scale: horizontal length of photograph = $840 \mu \mathrm{m})$

Table 1 Electron microprobe analyses for samples $v 1 m$ and $v 2 m$ (wt\%)

\begin{tabular}{|c|c|c|c|c|}
\hline \multirow[b]{2}{*}{ Oxide } & \multicolumn{2}{|c|}{ - VIm - } & \multirow{2}{*}{$\overline{\text { Magnemite }}$} & $2 \mathrm{~m}$ \\
\hline & Magnemite & IImenite & & Imenite \\
\hline$( \pm 0.06)$ & 69.83 & 46.84 & 72.29 & 48.12 \\
\hline $\mathrm{TiO}_{2} \quad( \pm 0.02)$ & 21.74 & 51.51 & 20.32 & 50.36 \\
\hline $\mathrm{Al}_{2} \mathrm{O}_{3}( \pm 0.06)$ & 1.74 & 0.08 & 1.86 & $<0.05^{*}$ \\
\hline Mgo $( \pm 0.08)$ & $<0.03^{*}$ & 0.59 & $0.02^{*}$ & 0.83 \\
\hline Mno $( \pm 0.05)$ & 0.64 & 0.64 & 0.64 & 0.62 \\
\hline Zno $\quad( \pm 0.04)$ & 0.24 & 0.24 & 034 & $<0.02^{*}$ \\
\hline Total $^{+}$ & 94.22 & 99.68 & 95.47 & 100.00 \\
\hline
\end{tabular}

* indicates that the value is below the detectable limit

+ Maghemite oxide wt\% totals fall below 100 because iron is presented as $\mathrm{FeO}$ rather than as $\mathrm{Fe}_{2} \mathrm{O}_{3}$

The degree of titanium substitution is high for the maghemite regions of both samples and a little aluminium, manganese and zinc is also present. No chromium substitution was detected.

Lattice parameters. The lattice parameter for the spinel-structure phase, from X-ray diffraction, is $0.8359(1) \mathrm{nm}$ for the sample from the basalt (V1m) and $0.8348(3)$ for the grains extracted from the weathered rind $(\mathrm{V} 2 \mathrm{~m})$. These values are both smaller than expected for a titanomagnetite with the observed $\mathrm{Fe} / \mathrm{Ti}$ ratio of $\approx 3.8(\approx 0.849 \mathrm{~nm}$; O'Reilly and Readman, 1971) but they are some- what larger than the accepted average value for end-member maghemite of $0.834 \mathrm{~nm}$. The decrease in lattice parameter may reflect further oxidation of any residual $\mathrm{Fe}^{2+}$ in the spinel as the rock weathers from the rind.

Magnetization. The saturation magnetization $\left(\sigma_{\mathrm{s}}\right)$ is $18 \mathrm{~J} / \mathrm{T} / \mathrm{kg}$ of sample for the opaque grains extracted from the basalt after crushing (V1m) and $25 \mathrm{~J} / \mathrm{T} / \mathrm{kg}$ for those in the rind (V2m). These figures fall within the expected range for soil maghemites ( $\leqslant 60 \mathrm{~J} / \mathrm{T} / \mathrm{kg}$; Coey, 1988).

Mössbauer spectroscopy. Room temperature Mössbauer spectra of V1m and V2m are shown in Fig. 3. They consist of three principal components; a magnetic sextet $\mathrm{M}$ with isomer shift (relative to $\alpha$-Fe) $\delta=0.32 \mathrm{~mm} / \mathrm{s}$, quadrupole shift $\Delta=-0.01 \mathrm{~mm} / \mathrm{s}$ and hyperfine field $\mathrm{B}_{\mathrm{hf}}=49.7 \mathrm{~T}$ and two quadrupole doublets, D1 with $\delta$ $=0.28 \mathrm{~mm} / \mathrm{s}$ and $\Delta=0.50 \mathrm{~mm} / \mathrm{s}$ and D2 with $\delta$ $=1.06 \mathrm{~mm} / \mathrm{s}$ and $\Delta=0.65 \mathrm{~mm} / \mathrm{s}$. Fit parameters and relative intensities of the three components are shown in Table 2. The ferrous doublet D2 is readily identified as ilmenite, for which $\delta$ $=1.07 \mathrm{~mm} / \mathrm{s}$ and $\Delta=0.68 \mathrm{~mm} / \mathrm{s}$ (Murad and Johnston, 1987). D1, which represents $22 \%$ of the relative absorption area in $\mathrm{V} 1 \mathrm{~m}$, but only $10 \%$ in $\mathrm{V} 2 \mathrm{~m}$ is identified as ferric iron in associated minerals. In addition there is a little ferrous absorption in $\mathrm{V} 1 \mathrm{~m} \quad(\delta=1.12(1) \mathrm{mm} / \mathrm{s}, \quad \Delta$ $=2.05(1) \mathrm{mm} / \mathrm{s})$ which is attributed to ferrous iron in the associated minerals. The magnetic sextet has a hyperfine splitting close to that of pure maghemite (49.9 T; Murad and Johnston, 1987). There is no sign of a separate ferrous pattern, or of the characteristic mixed-valence $\mathrm{Fe}^{2+} / \mathrm{Fe}^{3+}$ pattern found in stoichiometric or non-stoichiometric magnetite (Coey et al., 1971). The magnetically-ordered iron in the spinel-structure phase is apparently all $\mathrm{Fe}^{3+}$; from the quality of the fits, it can be affirmed that at most $10 \%$ of the iron in this phase could be $\mathrm{Fe}^{2+}$.

From the microprobe analyses in Table 1, the composition of the ilmenite is estimated to be $\left(\mathrm{Fe}_{0.99} \mathrm{Ti}_{0.98} \mathrm{Mg}_{0.02} \mathrm{Mn}_{0.01}\right) \mathrm{O}_{3}$ in $\mathrm{V} 1 \mathrm{~m}$ and $\left(\mathrm{Fe}_{1.01} \mathrm{Ti}_{0.95} \mathrm{Mg}_{0.03} \mathrm{Mn}_{0.01}\right) \mathrm{O}_{3}$ in $\mathrm{V} 2 \mathrm{~m}$, i.e. there is practically no difference from the ideal formula $\mathrm{FeTiO}_{3}$. The relative areas of the $\mathrm{M}$ and $\mathrm{D} 2 \mathrm{com}$ ponents of the Mössbauer spectra are $61: 17$ for $\mathrm{V} 1 \mathrm{~m}$ and $78: 10$ for $\mathrm{V} 2 \mathrm{~m}$, which correspond to a maghemite: ilmenite ratio of approximately $4: 1$ for $\mathrm{V} 1 \mathrm{~m}$ and $8: 1$ for $\mathrm{V} 2 \mathrm{~m}$ (assuming identical recoil-free fractions for maghemite and ilmenite). This ratio is in agreement with the optical estimates. The weathering process in the rind appears to remove ilmenite in preference to maghemite.

Taking all the iron in the maghemite to be $\mathrm{Fe}^{3+}$, this leads to the following compositions: 


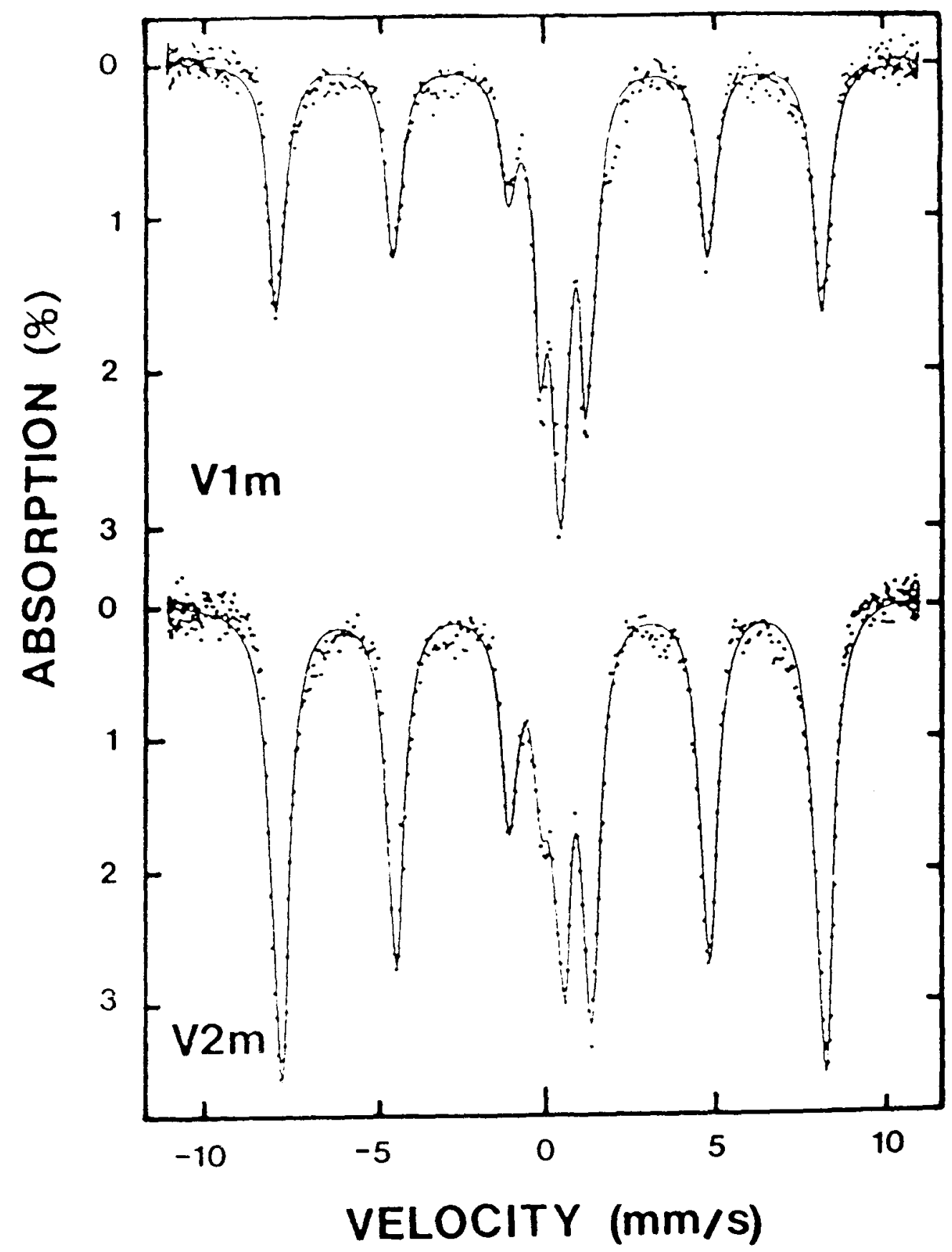

FIG. 3. Room-temperature Mössbauer spectra of the magnetic grains V1m (from the rock) and V2m (from the weathered rind). 


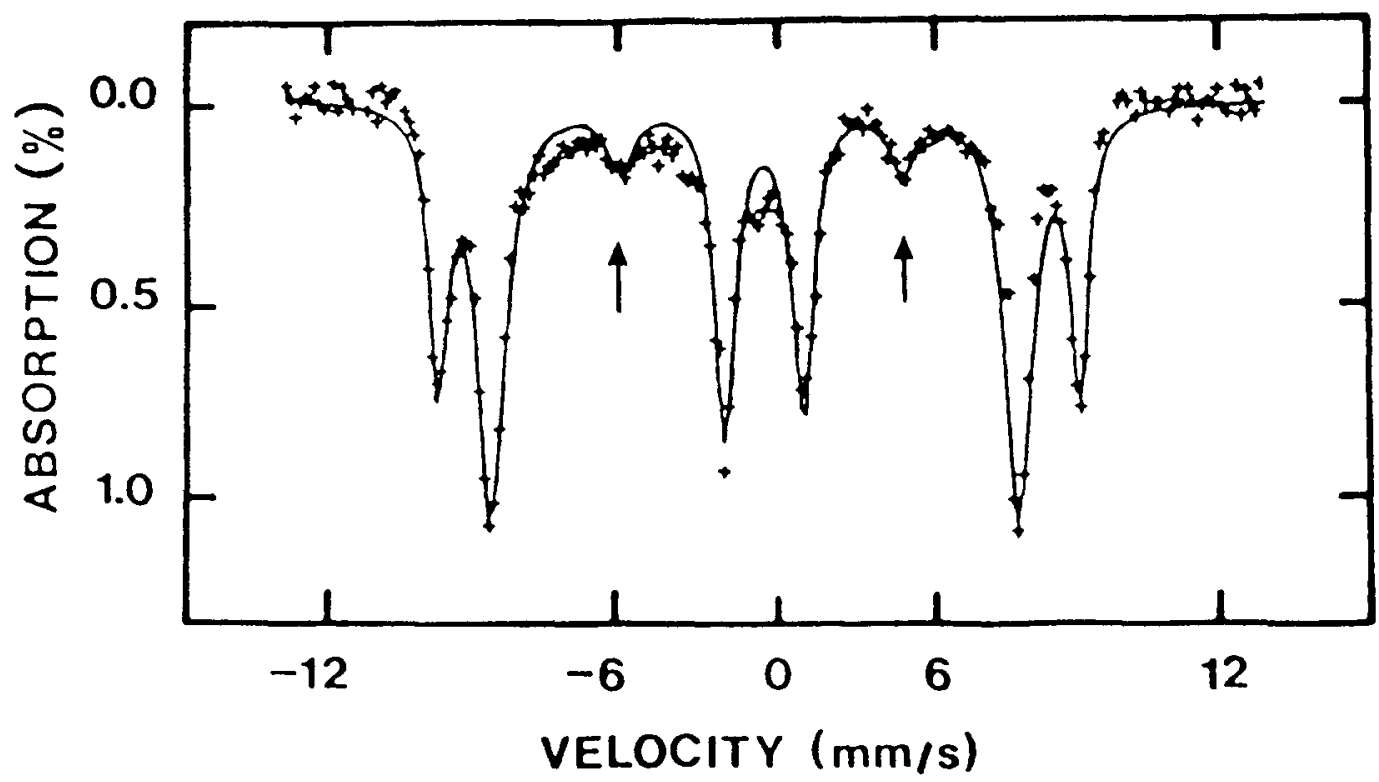

Fig. 4. Mössbauer spectrum of sample V2m at $4.2 \mathrm{~K}$ in an applied field of $5 \mathrm{~T}$ (the arrows indicate the positions of lines 2 and 5).

Table 2 Móssbauer parameters for $v 1 \mathrm{~m}$ and $\mathrm{V} 2 \mathrm{~m}$ at

room temperature

\begin{tabular}{|c|c|c|c|c|c|}
\hline & & $\partial^{*}(\mathrm{~mm} / \mathrm{s})$ & $\Delta(\mathrm{mm} / \mathrm{s})$ & $B_{h f}(T)$ & Relative area \\
\hline \multirow{3}{*}{ Vim } & M & $0.33(1)$ & $-0.02(1)$ & $49.7(1)$ & 0.61 \\
\hline & DI & $0.30(1)$ & $0.5 \mid\{1\}$ & - & 0.22 \\
\hline & $D 2$ & $1.07(1)$ & $0.63(i)$ & - & 0.17 \\
\hline \multicolumn{6}{|l|}{$v 2 m$} \\
\hline & $M$ & $0.32(1)$ & $-0.01(1)$ & $49.7(i)$ & 0.78 \\
\hline & DI & $0.26(1)$ & $0.48(2)$ & - & 0.10 \\
\hline & $\mathrm{D} 2$ & $1.05(1)$ & $0.68(1)$ & - & 0.12 \\
\hline
\end{tabular}

* a quoted relative to $\alpha$-Fe

$$
\mathrm{V} 1 \mathrm{~m} \quad\left(\mathrm{Fe}_{1.91} \mathrm{Ti}_{0.53} \mathrm{Al}_{0.03} \mathrm{Mn}_{0.02} \mathrm{Zn}_{0.01} \square_{0.50}\right) \mathrm{O}_{4}
$$$$
\mathrm{V} 2 \mathrm{~m} \quad\left(\mathrm{Fe}_{1.96} \mathrm{Ti}_{0.49} \mathrm{Al}_{0.03} \mathrm{Mn}_{0.02} \mathrm{Zn}_{0.01} \square_{0.49}\right) \mathrm{O}_{4}
$$

where $\square$ represents a vacancy.

A Mössbauer spectrum of $\mathrm{V} 2 \mathrm{~m}$ was also obtained at $4.2 \mathrm{~K}$ in an applied field of $5 \mathrm{~T}$ (Fig. 4). The main features are

(i) a splitting of the ferric sextet, separating the $A$ site and $B$ site iron sublattices and

(ii) reduction in the intensities of lines 2 and 5 of this pattern.

The ilmenite is also magnetically ordered at this temperature, with $\mathrm{B}_{\mathrm{hf}}=4.8 \mathrm{~T}$ (Murad and Johnson, 1987), but the applied field broadens the lines from the randomly-oriented and magnetically anisotropic antiferromagnetic ilmenite grains, so that its absorption contributes to the background in the range -1 to $+1 \mathrm{~mm} / \mathrm{s}$.

The presence of lines 2 and 5 of the maghemite spectrum (indicated by arrows in Fig. 4) shows that spin canting occurs. From computer fitting, the canting is found to be associated with the spectrum from the octahedral sublattice and an average canting angle of $32 \pm 3^{\circ}$ is deduced. The ratio of occupancies of tetrahedral to octahedral sites is derived from the intensities of the magnetically split subspectra (assuming equal recoilless fractions) to be $0.65(5)$.

Using this information, the formula for titanomaghemite in V2m may finally be rewritten as

$\left[\mathrm{Fe}_{0.77} \mathrm{Ti}_{0.22} \mathrm{Zn}_{0.01}\right]\left\{\mathrm{Fe}_{1.19} \mathrm{Ti}_{0.26} \mathrm{Mn}_{0.02} \mathrm{Al}_{0.04} \square_{0.49}\right\} 0_{4}$

Here we assume an $A$-site preference for $\mathrm{Zn}$ and a $B$-site preference for $\mathrm{Al}$ and $\mathrm{Mn}$.

The calculated saturation magnetization from this formula is $33 \mathrm{~J} / \mathrm{T} / \mathrm{kg}$ with the magnetic structure indicated in Fig. 5. This value agrees well with the magnetization of the titanomaghemite deduced from the experimental value corrected for the presence of ilmenite $(36 \mathrm{~J} / \mathrm{T} / \mathrm{kg})$.

The spin canting appears mostly on $B$ sites, because of the relatively greater non-magnetic substitution on $A$ sites in the above formula, and 


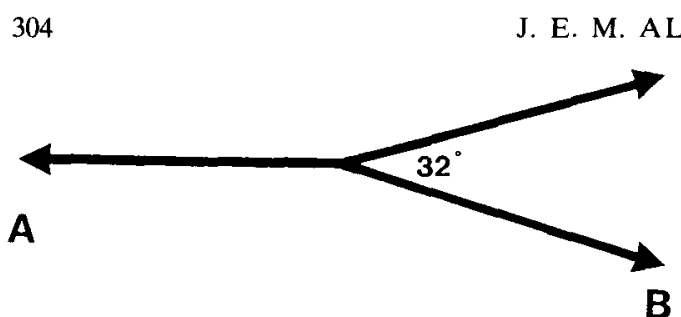

FIG. 5. The magnetic structure of titanomaghemite in $\mathrm{V} 2 \mathrm{~m}$ showing the directions of spins in the A and B sublattices.

the presence of a maximum of only four $A$ site superexchange neighbours of any $B$ site in the spinel structure (Coey, 1987). Spin canting will be significant for iron on those $B$ sites with only one or two $A$ site iron neighbours. The proportion of reversal spins associated with $B$ site iron with zero $A$ site neighbours will be neglible.

\section{Conclusion}

Petrographically fresh rock of basaltic composition has been found to contain highly-oxidized grains of titanomaghemite, which host exsolution lamellae of ilmenite.

The spinel has a canted spin structure, with canting mainly on the octahedral iron sublattice caused by substitution of non-magnetic ions, mainly titanium. The magnetization, $36 \mathrm{~J} / \mathrm{T} / \mathrm{kg}$, is only about half that of pure maghemite. The titanomaghemite is more resistant to weathering than ilmenite, and persists far into the soils formed from the basalt. Magnetic measurements may be useful to quantify it in this context.

\section{Acknowledgements}

JEMA and JMDC are grateful to Professor Mauro Resende of the Soil Science Department, University of Viçosa, Minas Gerais, Brazil, for introducing them to magnetic soils, for collecting the samples and for many enlightening discussions. We are also grateful to $\mathrm{Dr} \mathrm{E}$. Murad and the technical staff of the Institut für Bodenkunde, TU München, Freising-Weihenstephan, West Germany, for assistance with the Mössbauer and X-ray diffraction analyses. This work was supported in part by the National Board for Science and Technology (Ire- land) (SRP 117/84) and by the Deutscher Akademischer Austauschdienst (Germany) (DAAD 312/ 009/072/7).

\section{References}

Akimoto, S. and Kushiro, I. (1960) J. Geomag. Geoelect. 11, 94-110.

Coey, J. M. D. (1987) Can. J. Phys. 65, 1210-32.

(1988) In Iron in Soils and Clay Minerals (J. W. Stucki, B. A. Goodman, and U. Schwertmann, eds.), NATO ASI, 397-466.

- Morrish, A. H., and Sawatzky, G. A. (1971) J. Physique, 32 (C1), 271-3.

Colby, J. W. (1968) Adv. in X-ray Analysis, 11, 287-305.

Curi, N. and Franzmeier, D. P. (1987) Soil Sci. Soc. Am. J. 51, 153-8.

Fitzpatrick, R. W. (1988) In Iron in Soils and Clay Minerals (J. W. Stucki, B. A. Goodman and U. Schwertmann, eds.), NATO ASI, 351-96.

Hauptmann, Z. (1974) Geophys. J. R. Astron. Soc. 38, $29-47$.

Johnson, P. and Atwater, T. (1977) Geol. Soc. Am. Bull. 88, 637-47.

Kono, M., Clague, D. and Larson, E. E. (1980) In Initial Reports of the Deep Sea Drilling Project, 55 (E. D. Jackson et al., eds.), 639-52.

Kopp, O. C. and Lee, S. Y. (1987) Proc. Int. Clay Conf., Denver 1985 (L. G. Schultz et al., eds.), 205-11.

Lindsley, D. H. (1976) In Oxide Minerals (D. Rumble, ed.), Reviews in Mineralogy, 3, Mineral. Soc. Am., L1-84.

Murad, E. and Johnston, J. H. (1987) In Mössbauer Spectroscopy Applied to Inorganic Chemistry, 2, (G. J. Long, ed.), 507-82.

O'Reilly, W. and Readman, P. W. (1971) Z. Phys. 37, 321-7.

Putnis, A. and McConnell, J. D. C. (1980) In Principles of Mineral Behaviour, Geoscience Texts, 1, (A. Hallam, ed.), Blackwell, London.

Resende, M., Allan, J. E. M. and Coey, J. M. D. (1986) Earth Plan. Sci. Lett. 78, 322-6.

- Santana, D. P., Franzmeir, D. P. and Coey, J. M. D. (1988) In Proceedings of the Eighth International Soil Classification Workshop (M. N. Camargo and F. H. Beinrath, eds.), EMBRAPA, Brasilia.

Schwertmann, U. and Fechter, H. (1984) Soil Sci. Soc. Am. J. 48, 1462-3.

[Manuscript received 10 June 1988;

revised 16 November 1988] 